\title{
ARTIGOS
}

\section{VIDA E DIREITO ENTRE GIORGIO AGAMBEN E YAN THOMAS*}

\author{
Benjamim Brum Neto** \\ https://orcid.org/0000-0002-6797-0146 \\ benjamim.brum@gmail.com
}

RESUMO O presente artigo pretende explorar um tema ainda incipiente na literatura secundária referente ao estatuto do direito em Giorgio Agamben e ao peso do direito romano em seus trabalhos. Para isso lançamos mão do debate entre Agamben e Yan Thomas, um importante historiador do direito romano com quem Agamben teve um contato bastante intenso. Ao longo do artigo pretenderemos mostrar três coisas: em primeiro lugar, a relação de Agamben com a biopolítica, destacando, sobretudo, o aspecto articulatório da noção de dispositivo que subjaz suas investigações. Em segundo lugar, a importância do ensaio Vita necisque potestas de Yan Thomas, que servirá para Agamben introduzir diferenças em relação a Hannah Arendt e Michel Foucault. Por fim, lançaremos luz sobre o estatuto do direito no pensamento de Agamben, que, é a nossa hipótese, comunga da visão thomasiana: o direito não seria uma realidade metafísica ou substancial, mas funcionaria por meio de artifícios e ficções, o que nos permite pensar o direito enquanto um autêntico dispositivo biopolítico.

Palavras-chave Direito, Roma, biopolitica, dispositivo, arqueologia.

ABSTRACT This article intends to explore a still incipient theme in the secondary literature regarding the status of the law in Giorgio Agamben and

* Artigo submetido em 25/09/2019. Aprovado em 10/12/2019.

** Universidade Federal do Paraná. Curitiba, PR, Brasil. 
the weight of Roman law in his works. To this end, we have used the debate between Agamben and Yan Thomas, an important historian of Roman law with whom Agamben had a very intense contact. Throughout the article we will show three things: firstly, the relationship between Agamben and biopolitics, emphasising the articulatory aspect of the notion of apparatus which underlies his investigations. Then we will point out the importance of the essay Vita necisque potestas by Yan Thomas, which will serve for Agamben to introduce differences in relation to Hannah Arendt and Michel Foucault. Finally, we will shed light on the statute of law in Agamben's thought, which is our hypothesis, communes with the Thomasian view: law would not be a metaphysical or substantial reality, but would work through artifice and fiction, which enables us to think the law as an authentic biopolitical apparatus.

Keywords Law, Rom, biopolitics, apparatus, archeology.

\section{Introdução: sobre Giorgio Agamben e Yan Thomas}

Giorgio Agamben e Yan Thomas foram amigos por 13 anos: de 1995, ano em que Agamben lera pela primeira vez um texto de Thomas, até 2008, ano da morte do professor e diretor de estudos da EHSS e criador e diretor do Centre d'étude des normes juridiques. No decorrer desse período, dentre os diversos temas e questões que animaram o diálogo entre ambos os intelectuais, talvez o mais evidente, ao menos no que diz respeito ao interesse de Agamben pela obra do jurista, seja o da relação entre direito e vida. A respeito dessa preocupação compartilhada, Agamben escreveu em Autoritratto nello studio: "Como eu, Yan desconfiava das tentativas do direito de articular-se com a vida, de transformar imediatamente o vivente em um sujeito jurídico e, todavia, não podia não admirar os artifícios e as ficções através dos quais o direito romano teria respondido a esta tarefa" (Agamben, 2017a, p. 68). ${ }^{1} \mathrm{O}$ texto, Vitae necisque potestas. Le père, la cité, la mort, publicado na coleção Du châtiment dans la cité. Supplices corporels et peine de mort dans le monde antique em 1982, lido apenas em 1995 por Agamben, causou tamanha impressão no filósofo italiano que o levou a dedicar a ele imediatamente um subcapítulo do volume inaugural de Homo sacer. Vale notar que dentre os mais diversos estudiosos do mundo antigo presentes na bibliografia de Homo sacer, passando por Bickermann, Crifò, De Romilly, Ehrenberg, Fowler, Fugier, Strachan-Davidson, Vernant, 
Gernet, Glotz, Noailles e pelo próprio mentor de Thomas, André Magdelain, apenas Thomas teve um subcapítulo dedicado à discussão de um trabalho seu. ${ }^{2}$ No entanto, nossa pesquisa, que está longe de pretender esgotar todos os pontos de conexão possíveis entre os estudos desses dois grandes pensadores, baseou-se em outros dois textos de Agamben especificamente sobre Thomas. O primeiro desses textos com o qual tivemos contato é o prefácio intitulado Tra diritto e vita que Agamben escrevera para a tradução para o italiano do ensaio de Thomas La valeur de choses sob os cuidados de Michele Spanò em 2017. O segundo texto ainda permanece, se não desconhecido, ao menos muito pouco consultado. Trata-se de um texto que Agamben escrevera para uma coletânea de artigos sob direção de Paolo Napoli dedicados especificamente a Yan Thomas. A coletânea foi intitulada Aux origines des cultures juridiques européennes. Yan Thomas entre droit et sciences sociales e o título do texto de Agamben retoma novamente a temática comum a ambos: La vie et le droit.

Há outras importantes menções ao trabalho de Thomas nos textos de Agamben. Cabe um destaque para a influência de Thomas na investigação e escrita de Altisima povertà, que viera a público apenas em 2011, mas que já em 2007 Agamben teria assistido a um seminário conduzido por Thomas precisamente sobre o tema da vida monástica. Podemos também destacar o papel estratégico que a leitura que Thomas realiza acerca dos frutos do trabalho do escravo tem na meticulosa argumentação de Agamben em Uso dos corpos para pensar o caráter fundamentalmente sem obra do homem. Além disso, mesmo com a morte de Thomas, Agamben continua a dialogar com sua obra: esse é o caso de um de seus livros mais recentes, no qual Thomas não apenas se encontra entre outros autores fundamentais à sua reflexão - como Meillet, Benveniste e Carl Schmitt -, mas parece ocupar lugar de destaque, tendo inclusive um tom de palavra final no assunto. Refiro-me a Karman: breve trattato sull'azione, la colpa e il gesto.

Ao longo deste artigo pretenderemos apenas mostrar três coisas: em primeiro lugar, a importância do ensaio Vita necisque potestas de Yan Thomas, que servirá para Agamben introduzir diferenças em relação a dois de seus mestres. De um lado, Agamben parece imitar um gesto arendtiano de mostrar os destinos políticos designados por certas traduções de termos gregos para o latim. Um exemplo do emprego dessa "metodologia" em Arendt é o caso da substituição

2 Vale dizer que outra figura importante do mesmo círculo de Thomas desempenhará um papel de destaque no volume dedicado à stasis. Assim como Yan Thomas aparece nas obras de Agamben como um mestre da antropologia e direito romano, Nicole Loraux é uma referência chave para Agamben interpretar a relação entre oikos e pólis na sociedade grega. 
do político (politikon) pelo social (socialis). Segundo a filósofa, "melhor do que qualquer teoria elaborada, essa substituição inconsciente do político pelo social revela até que ponto havia sido perdida a original compreensão grega da política" (Arendt, 2017, p. 28). ${ }^{3}$ Como veremos, desde a primeira página da introdução de Homo sacer Agamben realiza um gesto análogo ao da filósofa. Muito mais do que uma grande teoria sobre uma concepção de vida, o que está em questão para Agamben é a substituição inconsciente da tradução do termo vida para o latim, ${ }^{4}$ sendo acrescido a ele um sentido ainda inexistente no mundo grego, um sentido propriamente jurídico. Em contrapartida, tocando a temática da relação entre o direito e a biopolítica, veremos que a noção de biopolítica com Agamben aparece conectada ao direito romano de uma forma paradigmática, sobretudo por meio da articulação feita por ele entre o poder soberano com a vida nua, aqui ilustrada a partir da ideia do filho varão. $\mathrm{O}$ saldo desses dois primeiros momentos é a ideia do direito como um dispositivo biopolítico, isto é, uma forma de articulação entre o vivente e os códigos. Por fim, pretendo lançar alguma luz sobre o estatuto do direito no pensamento de Agamben, que, é a nossa hipótese, se aproxima, se não totalmente ao menos em alguns aspectos, da visão thomasiana: o direito não seria uma realidade

3 A respeito dessa tradução inconsciente desacompanhada da experiência afirma Arendt: "essa relação especial entre a ação e estar junto parece justificar plenamente a antiga tradução do zoon politikon de Aristóteles como animal socialis, que já encontramos em Sêneca e depois, com Tomás de Aquino, tornou-se a tradução consagrada: homo est naturaliter politicus, id est, socialis ('o homem é, por natureza, político, isto é, social') [...][...] Para tanto, é significativo, mas não decisivo, que a palavra 'social' seja de origem romana e não tenha equivalente na língua ou no pensamento gregos. Não obstante, o uso latino da palavra societas tinha também originalmente um significado claramente político, embora limitado: indicava uma aliança entre pessoas para um fim específico, como quando os homens se organizavam para dominar outros ou para cometer um crime. É somente com o ulterior conceito de uma societas generis humani, uma 'sociedade da espécie humana', que o termo 'social' começa a adquirir o sentido geral de condição humana fundamental. Não que Aristóteles ou Platão ignorassem ou não dessem importância ao fato de que o homem não pode viver fora da companhia dos homens, simplesmente não incluíam tal condição entre as características especificamente humanas. Pelo contrário, ela era algo que a vida humana tinha em comum com a vida animal, razão suficiente para que não pudesse ser fundamentalmente humana" (Arendt, 2017, pp. 28-29). Também é valido mencionar que essa estratégia já estava presente em Heidegger e será muito importante para Agamben no decorrer de sua obra. No caso de Heidegger, basta lembrarmos do questionamento que ele fará da latinização dos termos

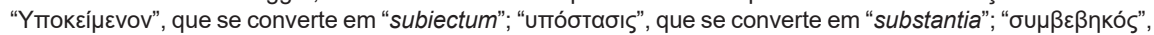
que se converte em "accidens". Nesse sentido, afirma Heidegger: "Essa tradução dos nomes gregos para a língua latina não é de modo algum o acontecimento sem consequências pelo qual ainda é tido nos dias de hoje. Muito antes, por detrás da tradução [Übersetzung] aparentemente literal e assim fiel, acoberta-se um transpor [Übersetzen] da experiência grega em uma outra forma de pensamento. O pensamento romano toma posse das palavras gregas sem a correspondente experiência cooriginária daquilo que elas dizem, sem a palavra grega. O desenraizamento [Bodenlosigkeit] do pensamento ocidental começa com esse traduzir (Heidegger, 1977, p. 8. Tradução nossa). A estratégia de Agamben para aceder ao nível biopolítico partirá justamente da tradução dos termos gregos zoé e bíos para o correspondente latino vita.

4 Não entraremos neste artigo na recepção de Agamben da noção de vida de um modo geral, notadamente no que diz respeito às noções de vida em Aristóteles. Nesse sentido, vale a pena consultar o primeiro capítulo do livro Política e tempo em Giorgio Agamben de Jonnefer Barbosa. O que nos interessa mais precisamente aqui é a discussão a partir já do termo latino vita. 
metafísica ou substancial, mas funcionaria por meio de artifícios e ficções. $\mathrm{O}$ direito opera criando realidades sobre as quais suas "coisas" vêm à existência. O direito, para ambos os autores, se inscreve no paradigma da "fala eficaz". Como resultado, pretendo abrir uma via de compreensão do direito a partir desses dois autores que nos permita relançar o direito numa chave biopolítica, não tanto em termos de uma "hermenêutica biopolítica", mas antes em termos de dispositivo. ${ }^{5}$

\section{Agamben e a biopolítica}

Como se sabe, Agamben ficou bastante conhecido na filosofia política contemporânea em função de suas incursões no campo de investigação da biopolítica aberto por Michel Foucault. O ponto central e mais comentado de sua leitura é que a biopolítica não seria um fenômeno político recente, porém algo conectado aos fundamentos do pensamento político e metafísico ocidentais. Sua arqueologia, como o filósofo italiano deixou claro no epílogo de Uso dos corpos, "não se propunha a criticar nem a corrigir esse ou aquele conceito, essa ou aquela instituição política ocidental; tratava-se, sim, de rediscutir o lugar e a própria estrutura originária da política, a fim de trazer à luz o arcanum imperii" (Agamben, 2017b, p. 295). Já aí encontramos uma afirmação que um foucaultiano jamais aceitaria. Em primeiro lugar, Agamben parece deixar de lado as relações produtivas dos saberes-poderes cujas articulações, sobretudo a partir do que Foucault chama de idade clássica, produziram transformações nos mecanismos de poder, dando origem então à era do biopoder. Agamben volta-se à estrutura e ao lugar próprio da política, lançando mão inclusive do termo "originário", que é bastante estranho à Foucault. Em segundo lugar, Agamben aposta numa imbricação muito mais forte e explícita entre poder soberano e biopolítica do que Foucault. Enquanto o filósofo francês atrela o surgimento da biopolítica à emergência da noção de população e ao corpo espécie, Agamben relaciona a biopolítica à forma originária de captura da vida pelo poder soberano. Em terceiro lugar, a biopolítica para Agamben não se limita a um fenômeno histórico, mas observa um tipo de operação constante no pensamento ocidental que extravasa o jurídico ou o político, ou melhor, que atua a partir de sua zona de indistinção. Em quarto lugar, se

5 Não desenvolveremos em detalhes as implicações dessa oposição entre "hermenêutica biopolítica" e "dispositivo biopolítico", que merece um artigo próprio. Mas vale adiantar que a hermenêutica aqui se refere à abordagem de Roberto Esposito, que lança a interrogação sobre a biopolítica a partir de uma contradição semântica interna ao conceito. Essa abordagem hermenêutica, ao nosso ver, é divergente daquela de Giorgio Agamben, apesar de Esposito também ter um diálogo importante com a obra de Yan Thomas. 
Foucault destaca a formulação "fazer viver e deixar morrer" como a insígnia da biopolítica em oposição ao "fazer morrer e deixar viver" característico do poder soberano, Agamben parece menosprezar essa distinção, ${ }^{6}$ interpretando a biopolítica como tanatopolítica, ${ }^{7}$ isto é, como política que regula a vida por meio da morte, deixando de lado todo o aspecto de incentivo, proliferação e difusão da vida condizente com o que Foucault entende por biopolítica. Para o filósofo italiano, a fórmula foucaultiana caracterizadora das duas formas de poder - poder soberano e biopoder - se não entram de fato numa zona de indistinção, ao menos atuam de forma concomitante e dependente uma da outra. Somos levados então a entender que a biopolítica é, ao mesmo tempo, tarefa e fundamento do poder soberano, e que com ele se articula aos moldes de uma verdadeira máquina governamental. ${ }^{8}$

Nesse sentido, boa parte do que Agamben tenta fazer, sobretudo no volume inaugural da série Homo sacer, é buscar a origem ${ }^{9}$ biopolítica de nosso pensamento jurídico-político, o que o leva a pensar não apenas o modelo biopolítico do poder, mas também o ponto oculto de intersecção entre as técnicas

6 Segundo Romandini: "A riqueza primordial do conceito de biopolítica de Foucault consiste, sem dúvida, no múltiplo jogo de intensidades possibilitado pelos pares conceituais de fazer morrer-viver e deixar viver-morrer, conforme estes sejam oportunamente combinados em suas distintas manifestações históricas. Todavia, esta potencialidade do paradigma biopolítico se perde completamente com Agamben, e o conceito de "biopolítica" passa, sem registro de inventário por parte do autor, e sem que isso tenha sido suficientemente sublinhado até o momento, a tomar um matiz completamente unidimensional" (2012, p. 21).

7 Isso ao menos nos primeiros volumes da série Homo sacer. É verdade que a partir de O reino e a glória a biopolítica parece ganhar novos contornos em função do surgimento de uma certa noção de governo ainda praticamente inexistente em O poder soberano e a vida nua ou O que resta de Auschwitz. Apenas em Estado de exceção a ideia de governo surge, mas ainda sem a centralidade que ele adquire em O reino e a glória.

8 Esse aspecto da máquina governamental ganha contornos mais claros em $O$ reino e a glória.

9 Agamben, ao contrário de Foucault e em função de outros referenciais teóricos, como Benjamin, Heidegger e Arendt, não se furta ao uso da noção de origem, apesar de reter um sentido foucaultiano na compreensão da mesma. De um modo mais geral, Esposito resume bem como o termo deve ser compreendido em Agamben: "L'origine, in questo caso, piuttosto che chiusa in se stessa, o dissolta nel processo che ne deriva, ne costituisce il segreto punto di resistenza - come una scheggia arcaica conficcata nella contemporaintà, destinata nello stesso tempo a complicarla e a esplicarla nel suo significato più riposto. Ma la relazione va intesa anche in direzione inversa, dal presente al passato, nel senso che quest'ultimo acquista piena comprensibilità solamente se interrogato dall'angolo di visuale aperto in una stagione successiva. Come la contemporaneità è svelata dalla presenza eterogenea, al suo interno, di uno, o piú frammenti originari, cosí l'origine è riconoscibile, nella sua continua sottrazione a se stessa, vale a dire nei suoi differenti effeti di senso, solo a partire da uno sguardo contemporaneo: 'É qualche cosa del genere che doveva avere in mente Michel Foucault, quando scriveva che le sue indagini storiche sul passato no erano che l'ombra prodottta dalla sua interrogazione teorica del presente. Allo stesso modo Walter Benjamin, allorché scriveva che l'indice storico custodito dalle immagini del passato attesta che esse non potranno essere lette che a um momento determinato della loro storia" (Esposito, 2010, p. 238). No entanto, também Thomas pode ser visto como alguém que contribui para a elaboração do sentido do termo em Agamben. Nesse sentido, destacamos o seguinte trecho do texto Origine et transmission du droit, publicado no livro Les opérations du droit: "Aussitôt avancée, la notion d'origine se dissout dans ce qui, dès qu'il apparaît, apparaît comme ayant déjà un passé. Toute trace se perd de l'élan initial. Tout se passe comme si le premier instant du développement juridique n'avait pu être pensé autrement que dans l'oubli, et qu'ainsi fussent privées de valeur inaugurale, primitive, les phases ultérieures où, sans qu'on l'ait vi naître, le droit est déjà là. Dans originem atque processum, origo n'est qu'un présupposé de processus : ce n'est pas un événement singulien» (Thomas, 2011, p. 78). 
biopolíticas e o modelo jurídico-institucional de poder. É também nesse campo de investigação aberto por Agamben que nossa pesquisa se concentra. O meu interesse é justamente o de pensar o direito enquanto um dispositivo biopolítico. Isto é, pensar o direito não tanto como algo oposto, diverso das técnicas de regulação das populações, mas antes pensá-lo em sua articulação com a vida, como algo imanente às estratégias biopolíticas de governo da vida. É nesse aspecto que podemos aproximar os trabalhos de Giorgio Agamben ao de Yan Thomas. Também o historiador do direito romano parece pensar as formas legais e as tecnologias políticas sem uma demarcação precisa entre dois âmbitos distintos, de modo a pensar o direito não tanto em seu caráter fixo, estável e codificado das leis, mas antes de tudo a partir do que Pierre Thévenin muito astutamente nomeou de infrajurídico (Thévenin, 2014). Nesse sentido, o que interessa a Thomas no direito é, antes de tudo, os sistemas de expedientes, de medidas, de circunstâncias, suspensivas, provisórias, semijurídicas ou ainda infrajurídicas provenientes do jogo de ajustes práticos muito instáveis e impuros que se relacionam diretamente com as malhas do poder e com as estratégias políticas.

Não mais tão distante de Foucault, portanto, buscamos uma concepção de direito diferente daquela vigente no positivismo de Kelsen, entendendo o fenômeno jurídico como um produto de técnicas e artifícios que respondem a objetivos disciplinares e preocupações governamentais (Thévenin, 2014, p. 63). Muito além de pensar a relação fundamental entre a lei e a norma, acredito que Agamben e Thomas possam nos auxiliar a retomar o direito na chave de leitura dos procedimentos de normalização, ou melhor, de governamentalização da vida. ${ }^{10}$ É apenas apreendendo direito e vida a partir da pragmática de sua articulação que poderemos entender os fenômenos de normalização da vida, bem como a tendência de uma juridificação (giuridificazione) moderna

10 Foucault faz uma importante distinção entre o que ele entende fazer em relação à teoria do direito de Kelsen, que pode ser resumida no seguinte parágrafo entre uma preocupação com a "normatividade" (Kelsen) e as "técnicas de normalização" (Foucault). Em Segurança, território e população, Foucault afirma: "Vocês conhecem melhor do que eu a nefasta sorte da palavra 'normalização'. O que não é normalização? Eu normalizo, tu normalizas, etc. Vamos tentar descobrir, ainda assim, alguns pontos importantes nisso tudo. Em primeiro lugar, um certo número de pessoas que tiveram a prudência, nestes dias, de reler Kelsen percebeu que Kelsen dizia, demonstrava, queria mostrar que entre a lei e a norma havia e não podia deixar de haver uma relação fundamental: todo sistema legal se relaciona a um sistema de normas. Mas creio que é preciso mostrar que a relação entre a lei e a norma indica efetivamente que há, intrinsecamente a todo imperativo da lei, algo que poderíamos chamar de uma normatividade, mas que essa normatividade intrínseca à lei, fundadora talvez da lei, não pode de maneira nenhuma ser confundida com o que tentamos identificar aqui sob o nome de procedimentos, processos, técnicas de normalização. Diria até, ao contrário, que, se é verdade que a lei se refere a uma norma, a lei tem portanto por papel e função - é a própria operação da lei - codificar uma norma, efetuar em relação a norma uma codificação, ao passo que o problema que procuro identificar é mostrar como, a partir e abaixo, nas margens e talvez até mesmo na contramão de um sistema da lei se desenvolvem técnicas de normalização" (2008, p. 74). 
crescente e imediata da vida. Tendo isso em mente, o que orientou a presente investigação foi tentar entender em que sentido o direito pode ser visto como um dispositivo biopolítico.

Mas o que qualifica um dispositivo como biopolítico? Amparado nas digressões agambenianas sobre a teologia econômica em $O$ reino e a glória, ${ }^{11}$ podemos entender que para ele o dispositivo é aquilo que dissocia, porém ao mesmo tempo relacionando duas coisas. Em uma só palavra: um dispositivo é uma articulação. Um dispositivo biopolítico, portanto, seria aquilo que opõe, mas ao mesmo tempo conecta a vida à norma, à regra ou à lei. $\mathrm{O}$ essencial desse raciocínio é que essa conexão entre os dois elementos nunca implica uma coincidência entre eles. O dispositivo, afirma Chignola, organiza uma cisão (Chignola, 2017, p. 204). Pensar alguma coisa a partir de um dispositivo no registro agambeniano significa manter os termos da relação numa articulação que mantém sua heterogeneidade; é pensar a relação entre os termos sem confundi-los ou recair numa identidade sintetizadora; é também pensar os termos em questão a partir de uma perspectiva não substancialista, mas ficcional, no sentido de algo que foi meticulosamente articulado ao longo do tempo, sobretudo por especialistas. É nesse sentido que devemos entender a ideia de "captura da vida" pelo direito, sobretudo pela forte afirmação de Agamben segundo a qual "nos termos de Yan, o direito assegura seu controle sobre a vida por meio da exclusão da fictio que é a vida nua" (Agamben, 2015, p. 18). Tanto Agamben quanto Thomas procuram entender de que modo vida e direito são articulados, isto é, "a divisão - e, ao mesmo tempo, a possível confusão - entre direito e vida" (Agamben, 2015, p. 8).

Para isso, buscaremos agora detalhar a leitura que Agamben faz de um texto de Thomas a fim de lançar luz sobre um dos momentos privilegiados da confecção dessa articulação entre direito e vida.

\section{Vitae necisque potestas}

Em $A$ vontade de saber, Foucault retoma o problema da lógica jurídica do poder que se restringiria a uma acepção negativa e repressiva. ${ }^{12}$ Como bem se sabe, o objetivo de Foucault é destacar um aspecto que ficara de lado nas teorias tradicionais do poder. Esse é o aspecto fomentador, incitador, difusor e produtor do poder, que por se concentrar sobre a vida biológica, sobre a vida

11 Para mais detalhes sobre a noção de "articulação" na obra de Agamben, cf. Brum Neto, 2017.

12 Referimo-nos aqui à imagem do direito a que Márcio Alves da Fonseca em Michel Foucault e o direito chamou de "primeira oposição entre direito e normalização" (Fonseca, 2012, p. 95). 
da espécie receberá o nome de biopoder. Mas o que mais nos interessa aqui é essa concepção negativa do poder, que é associada pelo filósofo francês ao poder soberano e que se define pelo direito de vida e de morte dos súditos. Numa rápida explanação acerca da origem arcaica desse direito de vida e morte, no último capítulo do livro de 1976 intitulado Droit de mort et pouvoir sur la vie, Foucault remete ao antigo patria potestas, instituto do direito romano que concedia ao pai o direito absoluto de "dispor" da vida de seus filhos e escravos (Foucault, 1976, p. 177). Apesar de Foucault entrever aqui uma possível analogia ou relação metafórica entre o poder do pater e o poder soberano, como passaremos a ver agora em mais detalhes, é somente Agamben que, tendo recurso ao texto de Thomas, consegue explicar a especificidade que faz do poder do pater servir de "célula originária" do poder soberano.

Nesse sentido, de acordo com Agamben, é preciso remontar justamente à expressão latina que captura o essencial do já revelado no subtítulo de Foucault: "a primeira vez, porém, [diz Agamben] que na história do direito, deparamos com a expressão 'direito de vida e morte', é na fórmula vitae necisque potestas, que não designa de modo algum o poder soberano, mas o incondicional poder do pater sobre os filhos homens" (Agamben, 2010, p. 88). O importante dessa noção - e é nisso que o artigo de Thomas contribui de forma original - é que essa instituição de Roma não se restringe à jurisdição doméstica, mas, "mesmo irrompendo imediatamente e unicamente da relação pai-filho ela desempenha um ofício público" (Agamben, 2010, pp. 88-89). É precisamente nesse sentido que Agamben parece seguir Thomas e destacar uma caraterística importante do poder soberano, a qual só poderia ser vista numa apreensão conjunta das formas legais com as tecnologias políticas. Segundo Agamben, o poder de vida e morte dessa expressão é muito mais do que uma mera metáfora ou analogia: "o que vale para o direito de vida e de morte do pater vale com maior razão para o poder soberano (imperium), do qual o primeiro constitui a célula originária" (Agamben, 2015a, p. 15). O pater, segundo Agamben e Thomas, tem seus discursos e suas representações ligadas às estruturas de parentesco, mas também às instituições públicas romanas (Dubouloz, 2018, p. 1). ${ }^{13}$

De acordo com Thomas, a expressão vitae necisque potestas visava particularmente ao poder incondicional do pater sobre os filhos homens (varões), o que de forma alguma pode ser confundido com o poder de matar conferido "ao marido ou ao pai sobre a mulher ou sobre a filha surpreendidas

13 «II est alors légitime de faire l'hypothèse qu'au-delà d'un simple usage métaphorique du terme pater, la paternité, ses représentations, ses discours se construisent à Rome à la fois dans les structures de la parenté et dans les institutions». 
em flagrante adultério, e ainda menos com o poder do dominus sobre seus servos" (Agamben, 2010, p. 88). Ele é "absoluto e não é concebido nem como a sanção de uma culpa" (Agamben, 2010, p. 88). O deslocamento operado por Agamben, portanto, visa mostrar que a caracterização do poder a partir do domínio sobre a vida e a morte se deu, no âmbito do direito, originariamente com a expressão vitae necisque potestas, fazendo dela um ponto de partida a seu ver mais estratégico para a compreensão do que há de mais original no poder soberano, sobretudo pelo fato de que ela nos permitiria observar a dimensão propriamente política do poder paterno em Roma. De acordo com Thomas a vitae necisque potestas:

não pode ser interpretado fora do direito paterno que é tanto público quanto privado que transcende as divisões do pensamento jurídico moderno [...] No início o problema é jurídico. Um pater familias não é apenas chefe de um domus. Ele é também investido de uma função de Estado [...] A relação pai-filho é, então, singular: ela é ao mesmo tempo doméstica e política, privada e pública. Se não levarmos em conta essas estruturas jurídicas elementares corremos o risco de tomar Roma por Atenas, de crer que todos os cidadãos seriam iguais perante a lei. $\mathrm{O}$ direito público romano tem como sujeitos de pleno exercício apenas os pais, quer dizer os sui iuris: os outros cidadãos, que são filhos, têm acesso à vida pública apenas por meio (voluntas patris ou peculium) dos primeiros (Thomas, 1984, pp. 528-529).

Como sabemos, a vida sagrada, isto é, a vida contra a qual não se pode cometer homicídio - pois sua morte não surte consequências jurídicas - ou levar à sacrifício é retida por Agamben como aquilo que caracteriza a vida sob o jugo do poder soberano. A vida do filho varão é tomada como o paradigma da vida que está sujeita a um momento de indecidibilidade e de indeterminação expressa por uma dupla excepcionalidade, que não se exerce apenas no âmbito da casa ou da cidade. É nesse sentido que Agamben interpreta a vida do filho varão em Roma como uma das figuras que pode ser abarcada pela noção de vida nua. ${ }^{14}$ Segundo Agamben,

Yan mostrava que justamente a fórmula vitae necisque potestas era também a única aparição do termo "vida" como conceito jurídico no direito romano. Nessa fórmula, todavia, vida é apenas a contraparte e quase a sombra de nex, isto é, do poder de matar sem derramamento de sangue. Segundo a demonstração de Yan, que a vida comparecesse no direito somente por meio da possibilidade da morte violenta era uma inesperada

14 Nas palavras de Dubouloz «En deçà de l'institution de normes positives et d'un pacte social, à travers la potestas paternelle, l'ordre juridico-politique se saisit des individus par un double mouvement contradictoire d'inclusion et d'exclusion : d'un côté, être dans la puissance du père est la condition nécessaire de l'intégration dans la cité, de l'accès à la vita, la vie au sens politique et non pas seulement biologique du terme; de l'autre, cette politisation de l'individu - du fils, ici - se fait au prix d'un abandon de sa vie à l'ordre juridico-politique, d'une réduction dans les mains de son père à ce qu'Agamben appelle la 'vie nue' » (Dubouloz, 2018, p. 8). 
confirmação das teses sobre a vida nua que eu estava desenvolvendo em Homo sacer. Na mesma página, uma nota confirmava o caráter excepcional dessa inscrição da vida na ordem do direito: 'No Digesto vida é o fato biológico de viver ou o modo de vida; não é, em nenhum caso, um conceito jurídico’ (Agamben, 2015b, pp. 7-8).

Aqui também podemos compreender que ao contrário da estratégia de Foucault trata-se, para Agamben, de situar desde essa origem no direito romano, ou ainda mais precisamente, desde a criação de um sentido ${ }^{15}$ especificamente jurídico da noção de vida algo que permanecerá na história de nossa tradição política, mesmo que de forma mais ou menos consciente.

Acredito que amparado em Thomas, Agamben atribua à vida do filho varão em Roma o estatuto de paradigma do poder soberano, demarcando essa particular descontinuidade entre Atenas e Roma como um dos sintomas de uma novidade. Os juristas romanos, povo que, de acordo com Arendt, talvez tenha sido o mais político que conhecemos (Arendt, 2017, p. 9), fizeram muito mais do que traduzir para o latim os termos gregos zoé e bios. ${ }^{16}$ Ao transportar o termo vida para a fórmula vitae necisque potestas, a noção de vida é instituída numa nova relação com direito, relação essa que acresceria à vida um sentido propriamente jurídico ainda não encontrado em reflexões jurídicas precedentes. Divergindo de Arendt, portanto, que chega a afirmar em $A$ condição humana que "jamais existiu um domínio público entre os membros de uma família" (Arendt, 2017, p. 66), Agamben mostra que o poder soberano foge à regra das distinções que Arendt indicava como axiomáticas e evidentes em si mesmas na antiguidade, encontrado na relação pai-filho em Roma a prova disso.

Com suas incursões pelo direito romano, Agamben quer sugerir uma alternativa à fundação do poder político no Ocidente, que privilegia (ou

15 Aqui enxergamos, de forma sutil, um aspecto bastante importante do pensamento de Agamben que, sobretudo, em O reino e a glória (2011) será essencial para a compreensão do termo oikonomia. Trata-se de uma distinção que Agamben faz logo no início do capítulo "O mistério de economia" entre Sinn e Bedeutung, o primeiro correspondendo a "sentido" e o segundo a "extensão analógica da denotação". Tendo em vista justamente a localização desses momentos instituidores e inaugurais, criadores de sentidos aos termos é que essa distinção é importante. O trabalho de Agamben e talvez esse seja uma das orientações metodológicas de seu pensamento que mais se afasta de Foucault e se aproxima de outras tradições (Derrida, Benjamin, Schmitt, Arendt e Heidegger) - consiste, em certa medida, em corrigir, por meio dessa advertência linguística, a confusão feita pelos comentadores entre Sinn e Bedeutung. Trata-se, para Agamben, de marcar com o máximo de precisão possível o momento em que um termo ganhou um sentido, em vez de ter ocorrido apenas o mero translado de um conceito de um âmbito para outro. O momento em que um termo ganha um novo sentido num novo âmbito é anunciado por Agamben, tanto no caso da oikonomia em O reino e a glória (2011), como no caso da palavra vita em Homo sacer (2010), pelo anúncio de que este determinado termo se tornou terminus technicus nesse novo âmbito.

16 Lembramos aqui o início de Homo sacer. "Os gregos não possuíam um termo único para exprimir o que nós queremos dizer com a palavra vida. Serviam-se de dois termos, semântica e morfologicamente distintos, ainda que reportáveis a um étimo comum: zoé, que exprimia o simples fato de viver comum a todos os seres vivos (animais, homens ou deuses) e bíos, que indicava a forma ou maneira de viver própria de um indivíduo ou de um grupo" (Agamben, 2010, p. 9). 
denuncia) seus elementos constitutivamente jurídicos. O vínculo político originário não seria nem o da lei positiva, nem o do pacto social, mas a relação entre o poder soberano e a vida nua, que surge de modo paradigmático no direito romano, o qual lega como assinatura (cf. Agamben, 2008) à nossa tradição política um sentido jurídico até então inexistente à vida. É a vida enquanto detentora não mais meramente de um sentido biológico ou social, mas também de um sentido jurídico que surge como o fundamento de um vínculo entre direito e vida que vem se acentuando cada vez mais ao longo dos séculos. Não apenas o homo sacer, mas já também o filho homem é, aos olhos das instituições jurídico-políticas romanas, vida nua.

Por meio dessa recuperação de um sentido propriamente jurídico da vida, que não se deixa apreender pelas categorias do público ou do privado, do doméstico ou do político, mas que emerge precisamente dos pontos de indistinção das categorias tradicionais do pensamento político, Agamben pode tratar das descontinuidades entre o mundo helênico e o mundo romano.

Há ainda um outro aspecto que não deve ser menosprezado. O surgimento de um acréscimo de sentido (além do biológico ou social) ao termo vida acontece, no âmbito do direito, de forma articulada com o poder de morte. Segundo Agamben "nessa fórmula [vita necisque potestas], todavia, vida é apenas a contraparte e quase a sombra de nex, isto é, do poder de matar sem derramamento de sangue" (Agamben, 2015b, p. 9). Nex aqui diz respeito à possibilidade de morte violenta, porém sem derramamento de sangue. Ao que tudo indica, a constatação de que a vida comparece no direito somente por meio da possibilidade da morte violenta serve para Agamben de confirmação das teses que estava desenvolvendo em Homo sacer. O homo sacer, vale a pena lembrar, não consiste numa punição ativa, como numa condenação à morte, mas numa espécie de violência radical, que se traduz pela ideia de abandono e de desamparo completo que se dão não sob a forma de uma mera exclusão, mas antes sob a forma de uma exclusão-inclusiva. E uma característica bastante essencial da vida sagrada do homo sacer é precisamente a falta de efeitos que teria o seu sangue: incapaz, a uma só vez, de servir ao sacrifício, mas também de servir como indício ou prova de homicídio. Com suas incursões pelo direito romano, Agamben quer sugerir uma alternativa à fundação do poder político no Ocidente. Originalmente não seria nem o vínculo da lei positiva, nem o pacto social, mas o vínculo soberano, quer dizer, o produto que surge da zona de indistinção entre a casa e a cidade, entre o externo e o interno, entre o oikos e a pólis, entre o privado e o público. Este produto não é a vida natural, mas a vida exposta radicalmente à morte. É ela o elemento originariamente politizado. Por meio dessa genealogia, Agamben quer reforçar a sua tese segundo a qual apesar 
de tradicionalmente se considerar a pólis como o espaço político por excelência no Ocidente, o paradigma da biopolítica retira da pólis esse suposto privilégio, apontando então para o campo que se abre entre a casa e a cidade, entre a vida privada e a vida pública como o lugar precípuo da fundação política. A ideia de campo pode aqui nos auxiliar na compreensão desse fenômeno de indeterminação na medida em que ele deve ser entendido não apenas como alusão aos campos de concentração, que marcaram de forma histórica o auge - e não tanto a ruptura como pensa Arendt - do pensamento clássico no século $\mathrm{XX}$, mas também como um espaço de indeterminação de categorias clássicas e modernas (Agamben, 2010, p. 182). Como afirmamos no início deste texto, se o objetivo da arqueologia da política ou do direito empreendida por Agamben em Homo sacer era encontrar o lugar e a estrutura do poder político ocidental, esse lugar é o campo enquanto espaço de indeterminação entre dentro e fora, e essa estrutura é a da exceção enquanto dispositivo de articulação ficcional erguido pelas estruturas e fórmulas jurídicas que isolam os termos opositivos, mantendo-os sempre em relação.

\section{O estatuto do direito em Agamben e Thomas}

Podemos agora passar a traçar algumas proximidades entre Thomas e Agamben, que vão muito além do uso de ocasião de textos. ${ }^{17}$ Para além da temática da relação entre direito e vida, há uma característica da abordagem do direito em Thomas que se encontra no nível da linguagem e que subjaz às reflexões precedentes concernentes ao sentido das palavras. Trata-se de uma abordagem técnica do direito que o aproxima muito mais da ideia de um dispositivo do que de um "objeto ontológico". É por meio dessa concepção, por que não, "poética" do direito (no sentido de produtiva e criadora), que Thomas se afasta das vertentes mitológicas fundadoras da tradição clássica ${ }^{18}$ mitologemas hobbesiano do estado de natureza, por exemplo -, bem como de

17 Até onde pude constatar, apesar das trocas e amizade, Thomas menciona Agamben rapidamente num único artigo intitulado "Le sujet de droit, la personne et la nature. Sur la critique contemporaine du sujet de droit" (1998).

18 Thomas sempre enfatiza em seus trabalhos a importância da atenção que se deve ter com a casuística em detrimento do estudo das doutrinas. Seus trabalhos se concentram sobre as práticas jurídicas, e não sobre as ideias que visam organizar essas práticas e que acabam por tornar ininteligíveis o que há nelas de específico. Segundo Thomas, "De ce point de vue, qui n'est pas celui de I'histoire des doctrines, mais celui de la pensée pratique, sinon technique, du droit, une pensée qui n'apparaît qu'à condition qu'on la contextualise dans les affaires mêmes qu'elle régit» (Thomas, 2011, p. 158); "Croyant plus au terrain des pratiques qu'à celui des doctrines pour faire accéder à l'intelligence du droit, je vais envisager ces adages dans leur usage casuistique, comme instrument de résolution d'une question" (Thomas, 2011, p. 162); "Es por eso que no quise escribir una historia de las ideas y menos aún, una historia de las doctrinas. Quise más bien mostrar cómo, por medio de qué elaboraciones y a través del desvío de qué problematizaciones, objetos institucionales como la 
um direito romano compreendido em termos naturais aos moldes de Cícero. Há também um distanciamento notório em relação a autores contemporâneos, como no caso de Michel Villey, ${ }^{19}$ Ernst Kantorowicz ${ }^{20}$ e Hans Kelsen. Essa vertente técnica pensaria o direito a partir do artifício, compreendendo que no mundo nada é dado, mas, pelo contrário, tudo seria fabricado desde tempos longínquos por "especialistas em separação e divisão" (Thomas, 1999, p.10). Essa ideia parece ressoar numa afirmação bastante elucidativa de Agamben que aparece pela primeira vez em $O$ aberto: não tanto o mistério metafísico da conjunção, mas antes, desde seus primeiros livros, Agamben tem um interesse especial pelos "efeitos práticos e políticos da separação".

Nesse sentido, a investigação de Thomas, que assim como a de Agamben reivindica a arqueologia como método (cf. Brum Neto, 2018), não visa à "história das ideias ou história das doutrinas" (Thomas, 2011, p. 11). Enquanto arqueologia, a investigação do historiador do direito no caso de Thomas ou do lugar e da estrutura da política e do direito no caso de Agamben não visa a encontrar universais e objetos perenes na história, mas precisamente aqueles objetos institucionais, que possuem uma existência real e que regem nossos destinos numa larga duração, destacando, assim, seus aspectos poéticos, muito mais que os lógicos (Thomas, 2011, p. 237). O que importa ao arqueólogo é antes a casuística e a narrativa concreta, ou ainda, como o faz extraordinariamente Agamben no caso da oikonomia em $O$ reino e a glória, uma disputa pelos usos das palavras e expressões nas questões teológicas, e não tanto o raciocínio lógico e puro do normativismo que reduz o direito à subsunção vertical de

naturaleza, la persona, el sujeto, el trabajo, la prohibición, la filiación, el origen, la ley, etc., fueron promovidos a la existencia" (Thomas, 1999, p. 11).

19 A querela com Michel Villey se dá pelo fato dele encabeçar uma interpretação do direito que privilegia o direito natural em detrimento do direito positivo. Thomas, no entanto, defende a ideia de que para os romanos até mesmo a natureza é instituída, a fim de se conseguir determinados resultados. Mesmo se nos textos didáticos romanos a respeito do direito os princípios estoicos e ciceronianos são invocados, fazendo da natureza a fonte do direito, a casuística romana mostra outra coisa: que a natureza no âmbito técnico aparece apenas como obstáculo físico à lei, mas nunca como fonte de obrigação. Thévénin assim conclui: « Par-dessous les déclarations de facture cicéronienne se révèle donc l'absence de toute idée de subordination du droit de la cité à un droit naturel qui n'est invoqué que pour étendre son champ d'application et qui ne remplit jamais la fonction de source supérieure d'obligation » (Thévenin, 2009, p. 160). cf. Thomas, 1985, 1988 e 1991.

20 Apesar de sua declarada admiração pelo trabalho de Kantorowicz, Thomas sempre nos alerta para a estratégia de substancialização presente em seus textos, o que contraria a perspectiva técnica do direito, que apreende o fenômeno jurídico a partir de suas operações. Nesse sentido, afirma Thomas: «le souci de substantialiser la fictio est très net chez E. Kantorowicz» (Thomas, 2011, p. 309). Também: «il n'y a pas à nier la génialité d'E. Kantorowicz. Mais nombre de ses analyses, y compris celle des deux corps du roi, substantialisent à outrance des échafaudages politico-juridiques qui ne relèvent pas, fait-il le rappeler, de la causalité, mais de l'imputation. Ériger le monde des institutions dans une zone où l'invisible se mélange au visible, selon le modèle christologique et ecclésiologique, et à mi-chemin entre l'être et le non-être, fait perdre le sens de l'artifice, de l'arbitraire et, pour tout dire, de la liberté avec lequel les juristes, y compris ceux de la tradition scolastique médiévale, ont toujours considéré le phénomène juridique » (Thomas, 2011, p. 305). 
casos a normas. A tarefa arqueológica do historiador do direito no sentido que aqui pretendemos tomar é também devedora da filologia jurídica, lembrando que também para Agamben não há filosofia sem filologia (Agamben, 2014, p. 10): o arqueólogo, no caso dos dois autores, deve privilegiar as noções inscritas nas palavras e mais ainda nas fórmulas transportadas de um texto ao outro. É o que podemos notar a partir de uma entrevista concedida por Agamben a Patrick Boucheron a respeito do empreendimento arqueológico:

Você acaba de tocar num ponto absolutamente decisivo, que concerne a significação que tem para mim o trabalho do filólogo. O título da obra prima de um grande filólogo italiano, Giorgio Pasquali, é nesse sentido instrutivo: História da tradição e crítica do texto. Apenas o conhecimento crítico da tradição que nos transmitiu permite o acesso ao texto que nós queremos ler, mas este não é jamais original; não é senão apenas o que podemos alcançar remontando na contramão a história de sua tradição. Daí para mim a lição política da filologia. O que ela nos mostra, é que nós recebemos sem exceção nossa cultura - como aliás nossa língua - através de uma tradição histórica, que está já sempre mais ou menos conscientemente alterada e corrompida. O original não é o que o filólogo chama de arquétipo: à diferença deste, o original não se situa no passado, mas acontece no presente, no instante em que o filólogo se mede com a tradição num corpo a corpo que é necessariamente político e filosófico ao mesmo tempo. E é aqui que se insere o que eu gostaria de chamar com Michel Foucault de ponto de surgimento, que não coincide exatamente com a fonte que a tradição nos transmitiu. E é nesse ponto que o arqueólogo se separa do historiador, com o qual ele compartilhava até então o caminho e o método (Agamben, 2017c, pp. 8-9).

A tarefa do arqueólogo não é a de reconstruir ou tornar transparente um passado, uma sociedade; não se trata de explicar ou elucidar algo que se encontra lá no passado, as práticas sociais ou as leis tais como eram. O arqueólogo adentra um nível de interpretação das palavras, nomes e conceitos dos quais nem a própria sociedade que os utilizava parecia estar consciente. Dessa forma, percebe-se que o direito não é apenas um reflexo dos fatos e que seu caráter artificial provoca transformações na sociedade em que opera.

É por pensar o direito a partir de operações e de instituições de realidades que propomos uma leitura conjunta de Agamben e Thomas para entender o estatuto não apenas do jurídico, mas da arte jurídica em suas obras, e assim compreender uma questão que parece fundamental a ambos os autores. A aproximação entre eles é notada pelo próprio Agamben:

$\mathrm{Na}$ argumentação meticulosa de um grande historiador do direito encontrei o dispositivo da exceptio, da captura do fora, por meio do qual em Homo sacer havia definido a relação entre o direito e a vida. Nos termos de Yan, o direito assegura seu controle sobre a vida por meio da exclusão da fictio que é a vida nua, assim como o estado de exceção é o dispositivo por meio do qual o ordenamento jurídico, suspendendo temporariamente sua vigência, determina o âmbito normal de sua validade. A vida 
nua e o estado de exceção, como todo resultado de uma operação jurídica, são uma abstração e não uma realidade substancial (Agamben, 2017). ${ }^{21}$

Vemos nesse trecho uma porção de detalhes importantes, que nos convirá agora elencar. Em primeiro lugar, o que Agamben chama de exceptio se relaciona ao que Thomas chama de capacidade de abstração da linguagem jurídica. Essa abstração é a capacidade do direito de cindir e separar coisas de sua forma. O exemplo mais imediato que temos é precisamente o da vida nua, que, para Agamben, por definição, é uma vida que fora separada de sua forma (Agamben, 2017b, p. 295). A exceptio é justamente essa operação de isolamento ou de ficcionalização característico do maquinário jurídico. Em segundo lugar, Agamben acredita ter encontrado uma tese forte sobre o funcionamento do direito a partir dos limites que ele se autoimpõe. De acordo com Agamben, Thomas desconfia da forma como os juristas tradicionalmente pensam a questão dos limites do direito em relação aos assuntos humanos, "pois o direito funciona precisamente incluindo a exterioridade que ele instaurou ao colocar um limite. É preciso então, se quisermos nos opor à potência expansiva do direito, uma estratégia mais complexa (Agamben, 2013, p. 253). Ambos os autores parecem então estar de acordo sobre a necessidade de se pensar uma estratégia alternativa, que desative (no caso de Agamben) ou que desvie (no caso de Thomas) o dispositivo da exceptio. E Agamben prossegue:

Yan abre assim uma perspectiva quase vertiginosa sobre o funcionamento do direito, no qual o limens aparece como o dispositivo essencial da expansão da esfera jurídica: é situando provisoriamente fora do direito coisas e situações ou as assinalando como proibidas que o direito não cessa de assegurar seu domínio sobre os assuntos humanos. A proibição, como o estado de exceção, é aquilo a partir do que o direito pode a cada vez repercutir em seu avanço em direção aquilo que ele excluiu (Agamben, 2013, p. 258).

Em terceiro lugar, precisamos esclarecer, mesmo que rapidamente, o significado do termo técnico thomasiano "ficção", que, como afirmado por Agamben, corresponde ao estatuto da vida nua. Segundo Thomas, "com a ficção nós estamos na presença do mistério mais radicalmente estranho ao pensamento comum oferecido não pelo pensamento jurídico, mas mais precisamente à técnica do direito, sua maneira de fazer, a ars iuris" (Thomas, 2011, pp. 134-135). ${ }^{22}$ E comentando Thomas, Spanò afirma "Fictio é o nome do

21 Tradução de Vinícius Nicastro Honesko, disponível no blog: http://flanagens.blogspot.com/2017/04/entre-odireito-e-vida-giorgio-agamben.html (acessado em 01 de dezembro de 2018).

22 «Avec la fiction, nous sommes en présence du mystère le plus radicalement étranger à la pensée commune qu'offre, non pas la pensée juridique, mais plus précisément la technique du droit, sa manière de faire, l'ars iuris». 
modus operandi próprio do direito" (Spanò, 2015, p. 91). Esse mundo ficcional é para Thomas o mundo jurídico, o mundo da fala eficaz, que não se confunde com os fatos e com a natureza. É o mundo criado pela potência da linguagem humana, de seu aspecto performativo.

Neste ponto encontramos muitos ecos do início ao fim de $O$ sacramento da linguagem. Neste livro, Agamben levanta a hipótese de que o instituto do juramento, muito mais do que apenas colocar em jogo a veracidade de uma promessa ou de uma afirmação sobre algo passado (sobre o dictum, que é a parte semântica da promessa ou da asserção) carrega consigo uma característica arcaica da linguagem humana e que toca a própria natureza dos homens enquanto animais falantes (Agamben, 2011b, p. 15). Combatendo mitologemas científicos hegemônicos no Ocidente e que, segundo Agamben, teriam contaminado grandes obras de antropologia e sociologia históricas do século XX, o filósofo italiano enxerga essa dimensão arcaica da linguagem não como algo da ordem de uma substância religiosa, mas, invertendo a lógica, enxerga essa dimensão originária performativa da linguagem como aquilo que torna viável a existência do direito e da religião. Nos termos de Agamben: no juramento, direito e religião tecnicizam essa experiência da linguagem (Agamben, 2011b, p. 81). Há, para Agamben e Thomas, uma vis, uma força na palavra do direito em virtude da conservação dessa experiência performática original. ${ }^{23}$

Essas considerações nos levam por sua vez a uma concepção do direito longe de ser metafísica, substancialista, normativista, jusnaturalistas. É o próprio Thomas que nos dá uma luz de como compreender o fenômeno jurídico nesse paradigma da palavra eficaz:

Toda pesquisa inscrita numa perspectiva ontológica, a partir da questão 'o que é algo?', bloquearia a possibilidade de aceder às coisas do direito... é um erro de perspectiva considerá-las, como se fez com tanta frequência, do ponto de vista da física e da metafísica grega, uma vez que isso impede de ver como seu regime depende na realidade de uma constituição de seu valor (Thomas, 2015, p. 57).

23 No seguinte trecho observamos que Thomas identifica a relação entre língua e direito precisamente a partir da ficção de sua coincidência: «L'équiparation ita ut... ita, bien analysée comme fiction par Gaius, transforme ces paroles écrites en verbe. Fiction que les verba avaient été réellement prononcés, donc. Or cette fiction était nécessaire pour leur conférer force de droit. Dans la Loi des Douze Tables (450 avant J.-C.), les actes juridiques oraux opéraient avec l'efficace même du droit grâce à la fiction selon laquelle le verbe du citoyen avait valeur de droit : 'Ce que la langue a prononcé, cela sera considéré comme formule de droit' (VI, 1 : uti lingua nuncupassit ita ius esto) : comme si le citoyen - civis - eût été habileté à produire un droit - ius - par sa seule parole, ce qui met la fiction au principe même du ius civile, droit produit par le verbe du citoyen c'est-à-dire, droit de l'acte juridique. Du verbe à l'écrit, il fallait donc que l'écrit fût encore verbe » (Thomas, 2011, p. 149). 
Se é verdade o que dissemos, o direito, assim como a teologia, consiste numa esfera privilegiada de produção de assinaturas, no qual a eficácia do discurso excede seu significado ou o realiza (Agamben, 2009, p. 86). A partir de uma perspectiva artificialista do direito, podemos compreendê-lo como algo da natureza de um dispositivo, o qual, para garantir seu domínio sobre os homens, legou à nossa tradição jurídico-política um sentido sobre o qual detém prerrogativas. Muito mais do que um mero acréscimo de sentido, o dispositivo direito isola no vivente homem por meio da operação de exceção algo que o torna não apenas o produto originário do poder soberano, como também algo governável. O fascínio de Agamben e Thomas pelo direito reside precisamente nisso: enquanto artifício, o direito no ocidente atua como um dispositivo biopolítico que opera cindindo a vida do vivente e tornando-o governável. A resposta de Agamben para isso é precisamente aquela de pensar uma formade-vida, isto é, a vida que não pode ser separada de sua forma, o que exige por sua vez uma noção de direito ou um uso diferente do direito que não opere por meio do isolamento no vivente de algo como um sentido jurídico de sua vida.

\section{Conclusão}

Tendo por base essa comunhão de questões - temáticas e metodológicas - entre Giorgio Agamben e Yan Thomas, o que pretendi ter explicitado ao longo do texto foi antes de tudo uma perspectiva que acredito ser nova tanto no debate com estudiosos da obra de Agamben, quanto com juristas e historiadores interessados no estatuto do direito a partir de uma ars jurídica.

Nosso trabalho se desenvolveu em dois momentos. Num primeiro momento o que nos interessou mostrar foram as novidades introduzidas por Agamben a partir da leitura do patria potestas romano segundo as intuições do ensaio thomasiano Vitae necisque potestas. Ao que tudo indica, Agamben parece estar de acordo com as teses de Thomas, sobretudo no que diz respeito à dupla natureza (concomitantemente pública e privada) do vínculo que une pai e filho em Roma. A indistinção entre a casa e a cidade presente no modelo do poder absoluto que o pai exerce sobre o filho em Roma é algo que escapara a Hannah Arendt. Ao mesmo tempo, a partir de uma definição de biopolítica ligada à ideia de tanatopolítica, Agamben parece conseguir tomar a relação pai e filho em Roma como um paradigma do modelo soberano de poder que vem se constituindo no Ocidente por meio do vínculo entre direito e violência. Dessa forma, a biopolítica não pode ser considerada um fenômeno recente, mas algo que apesar de nos ser contemporâneo não deixa de certo modo de ser arcaico. Seguindo Agamben e a teoria das assinaturas que sua arqueologia reivindica 
como recurso metodológico, é o sentido jurídico da vida em sua formulação jurídico-biopolítica original que procuramos destacar. $\mathrm{O}$ direito se apresenta como um dispositivo biopolítico quando se torna capaz de isolar no vivente algo como um sentido jurídico de sua qualidade de ser vivente.

Num segundo momento pretendemos ter explicitado as proximidades entre Agamben e Thomas da ordem do modus operandi. O que nos interessou foi, sobretudo, o caráter não substancialista de apreensão do fenômeno jurídico. Nessa chave de leitura, ambos os autores parecem se voltar de forma crítica a toda uma forma dogmática de pensamento bastante enraizada e transformada em cânone. Enquanto arqueólogos - ou ao menos enquanto historiadores num sentido não tão tradicional do termo - Agamben e Thomas parecem optar pelos caminhos tortuosos da erudição e da complexidade, partindo de casos isolados para mostrar o alcance de inteligibilidade permitido por eles. $\mathrm{O}$ pressuposto de toda investigação de Agamben e Thomas é um cuidadoso trabalho com a língua, tendo em vista que o que nos torna humanos, ao menos para Agamben, é precisamente a nossa capacidade de estabelecer relações ético-políticas com ela.

Por fim, ao nos debruçarmos sobre o direito a partir dessa visão técnica, isto é, muito mais a partir das operações do direito, em detrimento do seu ser, acreditamos ser possível pensar o direito enquanto um dispositivo, isto é, como um dos elementos que reúne saberes e poderes que instituem categorias capazes de tornar nossas vidas governáveis. Dessa forma, talvez desviando um pouco das análises presentes em Homo sacer e nos aproximando um pouco mais das análises do governo biopolítico das populações de Foucault, acredito que Thomas nos permita construir mais pontes entre direito e biopolítica, sem precisarmos optar por um ou outro modelo de poder.

\section{Referências}

AGAMBEN, G. "Autoritratto nello studio". Milano: Nottetempo, 2017a. . "Categorias italianas: estudos de poética e literatura". Florianópolis: UFSC, 2014. . "Epílogo: por uma teoria do poder destituinte". In: Uso dos corpos. Tradução de Selvino J. Assmann. São Paulo: Boitempo, 2017b.

. "Homo sacer: o poder soberano e a vida nua". Belo Horizonte: Ed. UFMG, 2010. ."L'archéologue et l'historien. Dialogue avec Giorgio Agamben". Critique, Nr.

836-837, pp. 164-171, 2017c/1.

. "Meios sem fim: notas sobre a política". Belo Horizonte: Autêntica, 2015a.

. "O aberto: o homem e o animal”. Rio de Janeiro: Civilização Brasileira, 2017d. . “O que é um dispositivo?” In: O que é o contemporâneo? e outros ensaios.

Chapecó: Argos, 2009. 
. "O reino e a glória: uma arqueologia teológica da economia e do governo". São Paulo: Boitempo, 2011a.

. "O sacramento da linguagem: uma arqueologia do juramento". São Paulo: Boitempo, 2011b.

. "Signatura rerum: sur la méthode". Paris: Vrin, 2008.

"Tra il diritto e la vita". In: THOMAS, Y. Il valore delle cose. Macerata: Quodlibet. pp. 7-18, 2015b.

ARENDT, H. "A condição humana". Tradução de Roberto Raposo. Rio de Janeiro: Forense Universitária, 2017.

BARBOSA, J. "Política e tempo em Giorgio Agamben". São Paulo: Educ, 2014.

BRUM NETO, B. "Notas introdutórias à noção de arqueologia em Giorgio Agamben: deslocamentos interpretativos de Foucault". Trágica: estudos sobre Nietzsche, Vol. 11, pp. 92-110, 2018.

. "O paradigma da Oikonomia em Giorgio Agamben: entre o dispositivo e a máquina trinitária". In: Correia, A.; Nascimento, D.; Müller, M. C. Filosofia Política Contemporânea. Coleção XVII Encontro ANPOF: ANPOF, pp. 158-178, 2017.

. "Soberania e biopolítica em Giorgio Agamben". Dissertação de mestrado para obtenção do título de mestre em filosofia pela UFPR, 2016.

CHIGNOLA, S. "Sul dispositivo: Agamben, Foucault e Deleuze". In: Genealogie della modernità: teoria radicale e critica postcoloniale. Napoli: Meltemi, 2017.

DUBOULOZ, J. "Puissance de mort et puissance de vie du père romain sur son fils. Lecture croisée de Michel Foucault et de Yan Thomas". In. Une histoire au présent. Les historiens et Michel Foucault Damien Boquet, Blaise Dufal et Pauline Labey (dir.). pp. 41-58, 2013. [Online] Disponível em https://books.openedition.org/editionscnrs/24026 (Acessado em 23 de novembro de 2020).

ESPOSITO, R. "Pensiero vivente: Origine e attualità della filosofia italiana". Torino: Einaudi, 2010.

FONSECA, M. A. “Michel Foucault e o direito". São Paulo: Saraiva, 2012.

FOUCAULT, M. "Histoire de la sexualité I. La volonté de savoir". Paris: Gallimard, 1976. . "Segurança, território, população: curso dado no Collège de France (19771978)". Edição estabelecida por M. Senellart sob a direção de F. Ewald e A. Fontana; tradução E. Brandao; revisão da tradução C. Berliner. São Paulo: Martins Fontes, 2008. (Coleção Tópicos).

HEIDEGGER, M. „Der Ursprung des Kunstwerks“. In: Gesamtausgabe I. Abteilung: Veröffentlichte Schriften 1914-1970. Band 5, Holzwege. Frankfurt am Main: Satz und Druck: Limburger Vereinsdruckerei GmbH, 1977.

ROMANDINI, F. L. "A comunidade dos espectros. I. Antropotécnica”. Desterro: Cultura e Barbárie, 2012.

SPANÒ, M. "Le parole e le cose (del diritto)". In: THOMAS, Y. Il valore delle cose. Macerata: Quodlibet, 2015.

THÉVENIN, P. "Los infortunios de la infrajuricidad. El análisis de las normas de Foucault a Yan Thomas". Glossae. European Journal of Legal History, Nr. 11, pp. 52-64, 2014. [Online] Disponível em http://www.glossae.eu. 
THOMAS, Y. "Il valore delle cose". Macerata: Quodlibet, 2015. . "Imago naturae. L'institution de la nature". In. Théologie et droit dans la formation de l'État moderne, Rome, (coll. EFR 147), p. 241-278, 1991. . "Le sujet de droit, la personne et la nature. Sur la critique contemporaine du sujet de droit», Le Débat, Nr. 100, pp. 85-107, 1998/3.

. "Les opérations du droit". Paris: Gallimard, 2011.

. "L'institution juridique de la nature. Remarques sur la casuistique du droit naturel à Rome". In. Revue d'histoire des Facultés de droit et de la science juridique, 6, pp. 27-48, 1988.

. "Los artificios de las instituciones". Buenos Aires: Eudeba, 1999.

. "Michel Villey, la romanistique et le droit romain". In: Droit, nature, histoire, Aix-Marseille, pp. 31-41, 1985. 